\title{
Cd. Sahagún
}

Publicación semestral No. 11 (2019) 76-77

\author{
Auditoria Forense \\ Forensic Audit \\ Dorie Cruz-Ramírez ${ }^{a}$, Suly S. Pérez-Castañeda ${ }^{b}$, Víctor M. Piedra-Mayorga ${ }^{c}$
}

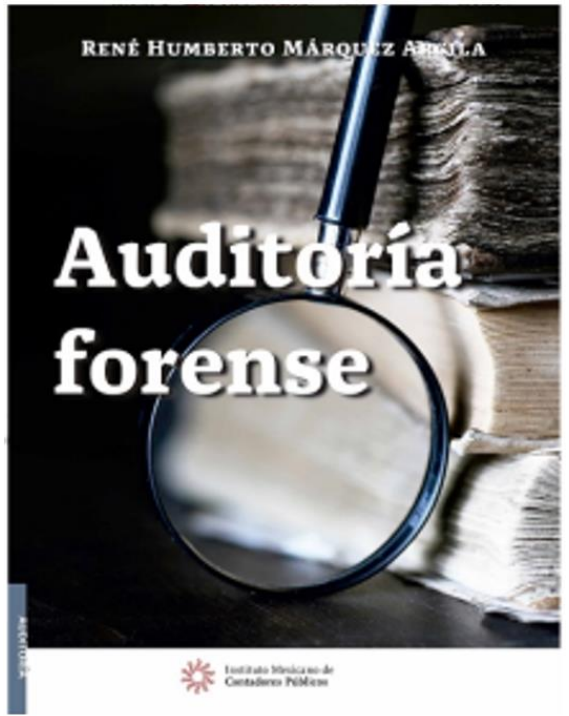

Derivado de los grandes fraudes corporativos a nivel nacional como internacional ocurridos en las últimas décadas, se pone entre dicho si los sistemas de control interno de las organizaciones son suficientes y sobre todo eficaces, por tal situación se han creado diversas normatividades y marcos regulatorios, así como comités y comisiones, con la finalidad de regular tanto a empresas del sector privado como del sector gubernamental, todo ello encaminado con el fin de combatir prácticas fraudulentas que pudiesen ser cometidas y afectar la credibilidad y patrimonio de las entidades y sus inversionistas.

Es por ello el surgimiento de la auditoría forense como una de las ramas de la auditoria y su interés radica en poder prevenir y detectar de manera oportuna posibles fraudes. Hablar de este tipo de auditoría, es hablar de la participación de diversas profesiones y profesionales con experiencia y conocimientos en áreas tales como criminalística, finanzas, contabilidad, jurídicos, informáticos, de ingeniería, etc.

Este libro permite de manera muy sencilla y clara entender conceptos indispensables sobre auditoria forense, se encuentra dividido en 3 capítulos, en el primero de ellos hace mención lo que representa un fraude corporativo, que indicadores determinan su existencia, el perfil tiene el defraudador, los diversos métodos para detectar su existencia, la manera de evaluar los riesgos de enfrentar un fraude, así como las consecuencias en las organizaciones y el impacto que tiene la auditoria forense, en su segundo capítulo se hace mención de la metodología que debe desarrollarse para poder realizar una auditoría forense y en su último capítulo se establece como generar un departamento de auditoría forense y toca temas

\footnotetext{
a Autor de Correspondencia, Universidad Autónoma del Estado de Hidalgo, Escuela Superior de Ciudad Sahagún, Email: doriec@uaeh.edu.mx

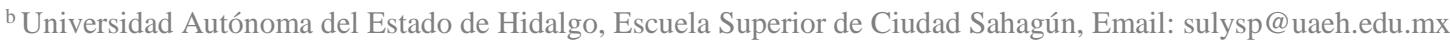

c Universidad Autónoma del Estado de Hidalgo, Escuela Superior de Ciudad Sahagún, Email: vmpiedra@uaeh.edu.mx
} 
de interés como son: cual debe de ser el perfil que de cumplir un auditor forense, cuáles son las asociaciones profesionales especializadas en fraudes, el marco legal internacional del fraude.

Es importante mencionar que algo que llama la atención de esta sugerencia bibliográfica es que, al finalizar cada capítulo de los temas abordados en cada uno de ellos, el autor presenta una serie de anexos donde expone de manera muy digerible ejemplos prácticos con la finalidad de que la información proporcionada pueda ser visualizada en la práctica.

Este material bibliográfico va dirigido a alumnos, (principalmente de quienes ya tienen conocimientos básicos de auditoría, y se encuentran analizando la auditoria forense como una auditoría específica) docentes, contadores, así como a cualquier persona interesada en conocer una nueva área de la auditoría.

\section{Referencia:}

Márquez, R. (2018). “Auditoria Forense” IMCP. México 